\title{
ESPACIOS DE LA ESCRITURA URBANA EN LA NARRATIVA DE GRISELDA GAMBARO
}

Cecilia Aberastury Universidad Nacional de la Patagonia Austral-UARG ${ }^{*}$

Un espacio de la lectura, o bien un particular espacio de la escritura ficcional. Dentro, sí, pero más allá del libro. Lo que aquí se quiere proponer tiene su origen en un efecto de lectura, que a su vez está relacionado con el modo de presentarse el espacio urbano del presente a través de la literatura y al mismo tiempo con la construcción de un espacio de la escritura ficcional en la narrativa de Griselda Gambaro. Ambas percepciones pueden pensarse desde la perspectiva que ofrecen las diversas reflexiones de Michel de Certeau, Marc Augé y Norbert Bolz sobre la ciudad como espacio privilegiado del presente, y Josefina Ludmer, desde una perspectiva centrada en la noción de "isla urbana" como clave de lectura para la contemporaneidad latinoamericana.

El espacio, entonces, de la discusión, será el de la gran ciudad. Norbert Bolz, en su ensayo "Theologie der Großstadt" (Teología de la gran ciudad), señala la indolencia, la reserva y la devaluación del mundo como las estrategias de inmunización propias del habitante de las urbes modernas. Allí “...el anonimato de las personas se corresponde con la falta de nombre de los escenarios. Desde que el mundo se ha convertido en gran ciudad, se vive fundamentalmente siempre en la misma: las metrópolis escenifican la simultaneidad mundial y l'état d'urgence" (Bolz, 1992).

Es en torno a esta experiencia constitutiva de la (post)modernidad urbana que se desarrollan los trabajos de Marc Augé y Michel de Certeau acerca de la definición del no-lugar, en el primero, o de la diferenciación entre lugar y espacio, en el caso del último. Siguiendo a De Certeau, un lugar es el orden según el cual

\footnotetext{
" Profesora en Letras por la Universidad Nacional de La Plata, profesora auxiliar de la cátedra de Teoría y Análisis Literario de la Universidad Nacional de la Patagonia Austral. Diplomada en Lectura, escritura y educación (FLACSO). Ha participado en proyectos de investigación en las áreas de Teoría Literaria y Literatura Argentina.
} 
los elementos se distribuyen en relaciones de coexistencia. Allí impera la ley de lo "propio": Ios elementos considerados están unos a otros, cada cual situado en su sitio "propio", distinto y definido. Un lugar es pues una configuración instantánea de posiciones. Implica una indicación de estabilidad.

Hay espacio en cuanto se toman en consideración los vectores de dirección, las cantidades de velocidad y la variable del tiempo. El espacio es un entrecruzamiento de movilidades. A diferencia del lugar, carece de la univocidad y de la estabilidad de un sitio "propio". En suma, el espacio es, para De Certeau (1979), un lugar practicado. De esta forma, la calle geométricamente definida por el urbanismo se transforma en espacio por intervención de los caminantes. Igualmente, el acto de la lectura es el espacio producido por la práctica del lugar que constituye un sistema de signos: lo escrito.

La ficción que ocupa el volumen Promesas y desvaríos (2004), de Griselda Gambaro desarrolla, llevando al extremo lo ensayado por la autora en novelas anteriores, un vaciamiento del lugar y los sujetos que coloca al lector ante el vértigo de un espacio sin límites, sólo dinámica. Puro origo de la escritura: aquí y ahora, aunque sin yo. Personajes sin nombre ni espesor biográfico o psicológico se mueven por un espacio innominado que reúne las características de la ciudad moderna - de la ciudad como escenario (o protagonista) de una modernidad excedida-. Más que escenario, suma o intersección de flujos: ${ }^{1}$ de información, de capital, de tecnología, y entre esas categorías la supervivencia de sujetos que nuevamente, como sucede ya en ficciones anteriores de Gambaro- tienen en común no tanto la marginalidad (que no es constante ni determinante) sino sobre todo la abyección. ${ }^{2}$ Resultados de la expulsión de una sociedad cuya existencia al

\footnotetext{
${ }^{1}$ Es por ello que para Harvey Cox, junto al tablero de control, cuya magia electrónica simboliza la comunicación total de los colectivos anónimos, hay un segundo gran símbolo más de la secular city: "el cruce-distribuidor de las autopistas [high-way cloverleaf], la imagen de la movilidad simultánea en diferentes direcciones". (Bolz, 1992).

${ }^{2}$ Lo abyecto, según Kristeva, es "una de esas violentas y oscuras rebeldías del ser contra aquello que lo amenaza y que le parece de un afuera o de un adentro exorbitante, expulsado más allá de lo posible, lo tolerable, lo pensable" (Kristeva, 1983:110). Esta primera aproximación al término se amplía luego introduciendo al sujeto en un cuerpo social: "Un 'algo' que no logro reconocer. Un peso de no sentido que no tiene nada de insignificante y que me aplasta. Al borde de la inexistencia y de la alucinación, de una realidad que si la reconozco, me aniquila. Lo abyecto y la
} 
mismo tiempo afirman, sus cuerpos recogen una identidad imposiblemente exterior a la insularidad que los define.

El espacio practicado por la acción y la lectura es el de la calle, el aspecto reconocible en los personajes, que apenas tienen en algún caso algo así como un nombre o mote, es su tránsito, precisamente su diferencia, quizás la confluencia asombrosamente fortuita y falta jamás de explicación en la casa del ciego, donde una suma de individualidades intersecta ocasionalmente sus trayectorias, sin dar por eso siquiera la ilusión de un conjunto. Esta azarosa comunidad responde en casi todos sus puntos a la de los pobladores de la isla urbana que describe Ludmer:

Los habitantes de la isla (los personajes que la narración puede multiplicar, fracturar, vaciar) parecen haber perdido la sociedad o algo que la representa en la forma de famila, clase, trabajo, razón y ley (y a veces de nación). Se definen en plural y forman una comunidad que no es la familia ni la del trabajo ni tampoco la de la clase social, sino algo diferente que puede incluir todas esas categorías al mismo tiempo, en sincro y en fusión. La isla constituye una comunidad que reúne a todas las demás; un grupo genérico de enfermos, locos, prostitutas, villeros, inmigrantes, rubios, monstruos o freaks, okupas. Están afuera y adentro al mismo tiempo: afuera de la sociedad, en la isla, y a la vez, adentro de la sociedad, que es lo social, donde se demarcan nítidamente los niveles y ocurre la historia y también la "subversión". (Ludmer, 2004:105)

La isla, podría arriesgarse, en ese estar dentro y fuera de la sociedad, al reunir los restos expulsados que a su vez la definen, aparece como un espacio de la abyección.

Un síntoma extendido de este desligamiento es asimismo el del anonimato tanto de las personas como del espacio urbano. La precisión en el

abyección son mis salvaguardas. Esbozos de mi cultura" (111-112). Por lo tanto, ese 'algo' considerado abyecto es el resultado de aquello que fue expulsado, eyectado, desterrado de mí, pero que me define, como cuerpo individual y social. Es, precisamente, ese movimiento a través del cual me expulso y me afirmo. Así, los personajes de Gambaro aparecen como productos de este proceso por el cual terminan convirtiéndose en lo opuesto, lo despreciable, aquello innombrable que no sólo les permite y otorga una identidad a partir de la diferencia, sino que dan cuenta de la identidad de ese todo que los produce y que intenta ocultarlos e ignorarlos. La única posibilidad que les queda a estos personajes anulados en su voz es convertir sus propios cuerpos en lenguajes de identidad. Es, precisamente, esa expulsión del cuerpo la que los incluye en un nuevo marco de pertenencia. 
nombre de las calles, barrios, hospitales, medios de transporte, de la ciudad misma queda excluida. Los espacios comparten el anonimato indiferente e irrelevante de los sujetos que los transitan: no se sabe, y pocas veces importa. El hospital es el espacio del nacimiento y la muerte masiva e indiferenciada, administrada y rotulada, hacia donde fluye una ritualizada masa a la espera de milagros seculares:

Tristán se sacudió la ceniza de la cara y cruzó hacia la vereda del hospital. Era un edificio grande y viejo, recorrido por tal multitud dominguera que parecía una kermesse. Pero sus entretenimientos no provocaban entusiasmo. Tristán se perdió en los pasillos y ya desesperaba cuando una enfermera de aspecto amable le indicó dónde podía encontrar al ciego. -Su papá- dijo, y tampoco le concedió tiempo para rectificación alguna. (PD, 58)

El anonimato es estrategia de defensa y de constitución de un espacio propio definido por su desarraigo e indeterminación -la cual paradójicamente se revela desde el comienzo desprovista de suspenso-. En las primeras líneas de la novela, en la presentación del ciego, la parquedad de la información no se basa en misterio alguno, sino en la suficiencia de un par de coordenadas más o menos laxas.

Lo llamaban el ciego de la otra cuadra y con esto se termina la intriga: era ciego. Si hubiera otra intriga sería de naturaleza geográfica; por comodidad el ciego siempre pertenecía a la otra cuadra, aunque los vecinos vivieran en la casa de al lado o fueran otros, distantes a cinco leguas. En cuanto al ciego, ignoraba cómo lo llamaban y que los vecinos le habian adjudicado una cuadra móvil y fugitiva. (PD, 9)

La definición del ciego a partir del nombre otorgado y el lugar de pertenencia, de los modos de adscripción y configuración tradicional del lugar, se caracteriza por su superficialidad e indeterminación. El ciego es una referencia móvil, una función difusa en la imaginación urbana: expulsado pero dentro, la otra cuadra es todavía el espacio compartido pero ya es otro lugar. El ciego es aquel que está en un lugar otro, insular, donde confluyen los demás personajes que transitan las páginas de Promesas y desvaríos. Tristán no se preocupa por averiguar el nombre del ciego, y tampoco en negar su filiación en el hospital, cuando ésta le sirve para encontrarlo: "su papá" es un mero rótulo, un nombre 
para la función, y mientras permita resolver la ecuación es útil. El no detenerse en explicaciones es un rasgo más de este extendido carácter de las figuras de la narrativa de Gambaro, oscilante entre la parquedad y la indolencia.

El anonimato es extensivo al espacio: la ciudad aparece como superficie y cruce de líneas de fuerza, condensadas en puntos especiales de convergencia (el hospital) o dispersándose en espacios móviles (el transporte ${ }^{3}$ ). A nadie más que al lector inquieta este anonimato, que una sola vez es puesto de relieve, casi al pasar, por los propios personajes: "Tristán oteó la noche, registró el foco anémico de la esquina, la ausencia de carteles que extraviaban la calle para los extraños, la volvían acertijo, senda perdida entre otras nombradas. Deseó para su anonimato carteles: luminosos, pintados sobre latas, garabateados con errores de ortografía sobre papeles volantes." (PD, 38).

Ante un lugar inmóvil, estático, conformado a partir de la coexistencia y contigüidad de elementos ubicados en un espacio que les resulta propio; ante un lugar que podría considerarse no sólo como identificación sino como productor de esa misma identidad que reúne y otorga cohesión a un grupo, y que debe ser protegida del afuera, de la amenazante diferencia del otro.

En este sentido, el referente se constituye en estos como un no-lugar. Su escritura da forma a ese espacio de lo innominado, de lo que puede asociarse a cualquier espacio urbano y a ninguno. Un no-lugar, en el sentido que a este término proporciona Marc Augé (1996:98) al distinguir el "lugar antropológico", en el cual "la identidad, las relaciones y la historia de los que lo habitan se inscriben en el espacio", del no-lugar característico de la "época contemporánea", identificado con "los espacios de la circulación, de la distribución y de la comunicación, donde ni la identidad, ni la relación, ni la historia se dejan captar".

\footnotetext{
3 "Antes de la formación de los ómnibus, ferrocarriles y tranvías en el siglo XIX, los hombres no estaban en absoluto en condiciones de poder o deber mirarse a lo largo de minutos y hasta horas, sin hablar entre sí. En lo tocante a la mayor parte de las relaciones entre seres humanos, el transporte moderno las abandona al solo sentido de la vista, y debe presuponer, con ello, condiciones completamente diversas para los sentimientos sociológicos generales. La (...) mayor incertidumbre del hombre sólo visto frente al oído resulte seguramente en un aporte (...) a la problemática del sentimiento de la vida, al sentimiento de desorientación en la vida común, del volverse cada vez más solitarios y que por todos los costados se esté rodeado de puertas cerradas" (G. Simmel. Philosophie des Geldes, Berlinm 1930:542).
} 
Si bien podría objetarse que una de las características de la sobremodernidad productora del no-lugar, tal como la describe Augé (1996), es la del exceso ${ }^{4}$ en las referencias y nomenclaturas que pueblan los espacios del tránsito y la transacción de las urbes modernas, y por lo tanto la falta que define a los personajes de Gambaro haría difícil la operativización de estas categorías en función de su lectura, ese exceso puede entenderse de todos modos en el origen de la falta del vínculo necesario entre los sujetos y las referencias, que constituye la historia, la pertenencia, el lugar. El exceso asume la forma de una saturación, un aturdimiento visual que engendra la falta.

Así, en las ficciones que nos ocupan, el espacio es enunciado (construido) al ser transitado por personajes desprovistos de pasado y sin perspectiva de futuro: anclados en un aquí y ahora (puro presente) que no les pertenece, figuras discordantes sobre el fondo de la experiencia urbana de la sobremodernidad $^{5}$ que no se incorpora como un paisaje propio y capaz de suscitar la serie de identificaciones que hace posible lo que llamamos identidad, en la medida en la cual es un espacio ajeno: no les pertenece ni los incorpora, aunque tampoco los expulsa del todo, dado que no ha llegado a poseerlos (son el

\footnotetext{
${ }^{4}$ En la sobremodernidad no hay lugar para el pasado. Con Augé, lo que es nuevo no es que el mundo no tenga o tenga poco o menos sentido, sino que experimentemos explícita e intensamente la necesidad cotidiana de darle alguno al mundo en general y no a alguna de nuestras particularidades. En esta necesidad de dar un sentido al presente, si no al pasado, Augé percibe el rescate de la superabundancia de acontecimientos que corresponde a una situación que llama de "sobremodernidad" para dar cuenta de su modalidad esencial: el exceso. De información, de imágenes y de subjetividad. La dificultad de pensar el tiempo, desde el punto de vista de la sobremodernidad, se debe a la superabundancia de acontecimientos del mundo contemporáneo, no al derrumbre de una idea de progreso desde hace largo tiempo deteriorada.

5 “¿Qué es lo que distingue a la sobremodernidad de la modernidad? La sobremodernidad no es el todo de la contemporaneidad. En la modernidad baudeleriana, por el contrario todo se mezcla, todo se unifica: los campanarios son los dueños de la ciudad. La imbricación de lo antiguo y de lo nuevo. La sobremodernidad convierte a lo antiguo (historia) en un espectáculo específico, así como los exotismos y todos los particularismos locales. En los no lugares de la sobremodernidad hay siempre un lugar específico para las "curiosidades" presentadas como tales. (...) El espacio de la sobremodernidad está trabajado por esta contradicción: sólo tiene que ver con individuos pero no están identificados, socializados ni localizados más que a la entrada y a la salida" (Augé, 1996:113-114).
} 
resultado de una expulsión, pero definen a aquello que los expulsa, su exterioridad es necesaria e imposible: en eso consiste lo abyecto). El relato nos posiciona frente al conflicto posible de lo que se dibuja como frontera, espacio de borde, tránsito, flujo, fuga (o puente, que suelda u opone alternativamente insularidades cambiantes). Por todo esto, la concepción de la isla urbana como modalidad contemporánea del territorio dentro de la ciudad y posibilidad de anclaje de la (des)identificación o de relación entre cuerpos y significaciones puede obtener una particular lectura en el relato de una ciudad despojada de tradiciones y demás tipos de referencias vinculadas a significaciones que vienen del pasado, en la que sus transeúntes obtienen su identidad a partir de los estigmas que los dejan fuera de la seguridad de un territorio. Josefina Ludmer piensa esta "isla urbana" como forma novedosa de ofrecerse el espacio de la ciudad latinoamericana contemporánea, modalidad que llama a la búsqueda de nuevas categorías para su análisis, dado que resiste la asimilación a los regímenes de significación hasta ahora provistos para ello:

La isla urbana no es un microcosmos, ni una metonimia ni reproduce la sociedad: su régimen no reconoce estos modos de representación y sentido. Es una fábrica de imágenes y enunciados territoriales, provisorios y ambivalentes: una secuencia sobre la irrupción de la naturaleza en la sociedad y al mismo tiempo un régimen de sentido. Satura la imaginación pública del presente (que preferimos en este momento imaginar como anónima y colectiva: a la vez un instrumento para hacer presente y un instrumento crítico) y permite pensar (o ver: el presente es el tiempo de la imagen y de la inmanencia) lo social sin la sociedad, lo histórico sin la historia y lo político sin la política. (Ludmer, 2004)

En la narrativa de Gambaro apenas puede vislumbrarse un exterior posible para esa insularidad urbana. El único personaje que alcanza a entrever la posibilidad de una situación diversa, una alternativa a la constante inmediatez, es -en Promesas y desvaríos- Toñito, quien por eso mismo traiciona y huye, o trasciende, y finalmente tienta el retorno.

El ansia de regreso de Toñito señala en su excepcionalidad la falta común al resto: no hay lugar al que regresar, sino que la abyección consiste en ese estar arrojado en el puro movimiento y la pura práctica y producción del espacio. La vuelta de Toñito tiende un puente en el sentido de De Certeau. Es él quien muestra la posibilidad de una alternativa, de un espacio ajeno al dado. La 
extrañeza, el aire de traición que tiene su partida y la indiferencia en su regreso hablan precisamente de esa alteridad hasta entonces ignorada. ${ }^{6}$ La indolencia característica del habitante de la gran ciudad, tal como se lo caracteriza desde Spengler y Simmel (cf. Bolz, 1992) es llevada por Gambaro a un extremo inquietante en la presentación de los personajes. La borradura del pasado es generalizada y se revela como angustia en la búsqueda de la calle por parte de Tristán, en el mismo párrafo referido más arriba: "Calle Los Álamos, Calle Los Álamos, repetía, con la esperanza de que el nombre llegara telepáticamente a su destino o impulsara el crecimiento de una hilera de viejos álamos, añosos, de cien años, desde el talonario amarillento hasta su puerta (...) Pero los árboles, como los carteles, brillaban por su ausencia" (PD, 38).

Todo regreso necesita de un pasado que lo provea de sentido. El lugar es tal por la tradición que le otorga significado (los álamos añosos que dan razón al nombre). La desmemoria de Tristán encuentra su correspondencia en la falta de asidero para el espacio que transita.

La narrativa de Griselda Gambaro revela así lugares (de la modulación y la construcción de un espacio, del espacio del relato mismo) que no responden al impulso hacia la creación de un todo orgánico (social, político, comunitario), de un espacio que nombre y delimite una totalidad representativa, sino a la manifestación de su desintegración. En efecto, la ficción, cada novela construye un nuevo espacio (en el sentido de De Certeau, en el cual cada lectura también lo constituiría a su vez, de otra forma, en espacio). Si el de Dios no nos quiere contentos podría identificarse sobre todo con el espacio liminar de lo abyecto (Aberastury, 2007), el de Promesas y desvaríos es el espacio de la urbe moderna, el de cosmópolis. Con Norbert Bolz:

\footnotetext{
${ }^{6}$ Una de las formas de entender el puente, de acuerdo con De Certeau (1979:140-141) es como "[t]ransgresión del límite, desobediencia de la autoridad del lugar, representa la partida, el perjuicio de un estado, la ambición de un poder conquistador, o la fuga de un exilio, de cualquier forma la "traición" de un orden. Pero al mismo tiempo erige ese otro lugar que confunde, deja o hace resurgir fuera de las fronteras la extrañeza que estaba controlada en el interior; da objetividad (es decir, expresión y representación) a la alteridad que se ocultaba de este lado de los límites, de manera que al volver a cruzar el puente y estar de vuelta en el recinto el viajero encuentra en lo sucesivo el otro lugar que primero había buscado al partir y que al regresar había huido en seguida" (De Certeau, 1979:140).
} 


\begin{abstract}
Las cosmópolis no son escenarios de historia de la civilización, sino medios de un hacerse móvil total: metabolismo de la sustancia urbana, arquitectura móvil, cinética urbana. Hace tiempo que la arquitectura de los aeropuertos se ha revelado como paradigma secreto de nuestras ciudades en tránsito - han convertido a los habitantes de la gran ciudad en eternos pasajeros, para quienes, en efecto, "habitar como transitivo" [Wohnen als Transitivum] se ha convertido en una verdad sobreentendida.
\end{abstract}

Cada novela abre un nuevo espacio, que no termina de dirimir límites con los anteriores. El espacio de la escritura responde también a una lógica de funciones, en la cual la primacía de uno no quita la co-presencia del otro. En sus trasvases y límites indefinidos estos vectores de la escritura coexisten, sin la consistencia de una saga homogénea, pero configurando un espacio peculiar. La narrativa reciente de Gambaro abre el juego para las potenciales prácticas de un espacio nunca fijado de manera definitiva, reconocible antes que nada en su carácter OTRO. No la estabilidad de lo propio, sino la inquietante extrañeza de lo abyecto, la indeterminación de un espacio que es también el de su escritura. El ejemplo más cabal es el de Tristán: cada vector de cada novela lo produce nuevamente, sin diferenciarlo ni definirlo ni oponerlo, sin un pasado, una genealogía o demás elementos identitarios precisos, termina haciendo dificultosa su identificación precisa en las distintas narraciones por parte del lector: el espacio de la lectura se asimila a la espacialidad anónima de la gran ciudad. EI lector, desorientado, ansía una calle cuyo nombre responda a sus árboles centenarios. 


\section{Bibliografía}

Aberastury, C. (2007): "Cuerpo y desposesión en Dios no nos quiere contentos, de Griselda Gambaro", en Espacios, №32; 2-5.

Augé, M. (1992): Los "no lugares". Espacios del anonimato. Una antropología de la sobremodernidad. Gedisa, Barcelona, 2000. (Traducción al español de Margarita Mizraji).

(1996): El sentido de los otros. Actualidad de la antropología. Paidós, Buenos Aires.

Bolz, N. (1992): "Theologie der Großstadt", en Die Großstadt als“Text”, Smuda, M. (ed.). Fink, Munich.

De Certeau, M. (1979): La invención de lo cotidiano. 1. Artes de hacer. Universidad Iberoamericana, México, 1999.

Gambaro, G. (1979): Dios no nos quiere contentos. Norma, Buenos Aires, 2003. (1994): Después del día de fiesta. Norma, Buenos Aires, 2005.

(2004): Promesas y desvaríos. Norma, Buenos Aires.

Ludmer, J. (2004): “Territorios del presente. En la isla urbana”, en Pensamiento de los Confines, $\mathrm{N}^{\circ} 15,103-110$.

Kristeva, J. (1983): “Aproximación a la abyección”, en Revista de Occidente, № 201, 1998:110-116. 